\title{
Reformas laborales cubanas en la prensa mexicana. Análisis crítico del discurso de La Jornada y Reforma
}

Cuban labor reforms in the Mexican press. Critical analysis of the speech of La Jornada and Reforma

COSETTE CELECIA PÉREZ

Doctora en Estudios Socioculturales y becaria del Programa de Becas Posdoctorales en la Universidad Nacional Autónoma de México (UNAM), en el Centro de Investigaciones Interdisciplinarias en Ciencias y Humanidades (Ceiich). Estudia actores y procesos emergentes que, apoyados en el empleo de las nuevas tecnologías de la información y la comunicación, reconfiguran el entorno de lo público. 



\title{
Reformas laborales cubanas en la prensa mexicana. Análisis crítico del discurso de La Jornada y Reforma \\ Cuban labor reforms in the Mexican press. Critical analysis of the speech of La Jornada and Reforma
}

\author{
Cosette Celecia Pérez \\ UNIVERSIDAD NACIONAL AUTÓNOMA DE MÉXICO \\ cosettecelecia@gmail.com
}

\section{PALABRAS CLAVE / KEYWORDS}

Reformas laborales en Cuba / Análisis Crítico del Discurso / prensa mexicana / discurso periodístico

Labor reforms in Cuba / Critical Discourse Analysis / Mexican press / journalistic discourse

\section{SUMILLA}

Abordar las transformaciones socioeconómicas promovidas en Cuba por el gobierno de Raúl Castro permite ahondar en las notables y dinámicas transformaciones que experimenta la isla desde hace una década. Este estudio aborda, desde el análisis crítico del discurso, el tratamiento que los diarios mexicanos La Jornada y Reforma dieron a la reducción de plazas laborales y la ampliación del trabajo privado en Cuba durante el periodo 2010-2011. El diseño metodológico mencionado, apoyado además en entrevistas, permitió identificar tanto el modo en que el poder se reproduce en los textos, como las mediaciones que el control estatal sobre la información en Cuba y los intereses editoriales de los rotativos mexicanos impusieron al proceso de construcción periodística.

\section{ABSTRACT}

Studying the socio-economic transformations promoted in Cuba by the government of Raúl Castro allows us to delve into the remarkable and dynamic transformations that the island has experienced for a decade. This article addresses, from the critical analysis of the discourse, the treatment that the Mexican newspapers La Jornada and Reforma gave to the reduction of jobs positions and the extension of private work in Cuba during the period 2010-2011. The aforementioned methodological design, also supported by interviews, made it possible to identify the way in which power is reproduced in the texts, as well as the mediations of the state control over information in Cuba and the editorial interests of Mexican newspapers, imposed on the process of journalistic construction. 


\section{Introducción}

Las transformaciones socioeconómicas promovidas en Cuba por el gobierno de Raúl Castro resultaron un suceso de gran interés nacional e internacional por significar cambios sustanciales en el modelo cubano. Por ejemplo, se ampliaron las actividades no estatales. Igualmente, se incluyó un reordenamiento laboral a través de la reducción de plantillas laborales infladas y el consiguiente despido de miles de trabajadores. Esta actualización del modelo cubano constituyó un proceso de aperturas que restituye, en el orden social, numerosas libertades civiles a los ciudadanos cubanos, derechos constreñidos hasta entonces, como la posibilidad de viajar al extranjero, hospedarse en hoteles o comprar y vender propiedades legalmente.

En agosto del 2010, el gobierno cubano anunció una medida que contemplaba el despido de más de 500 mil trabajadores estatales para marzo del 2011. En ese mismo lapso, planeaba sumar $465 \mathrm{mil}$ cubanos al sector privado, de los cuales 250 mil debían incorporarse al trabajo por cuenta propia. Esas dos medidas, la reducción de plazas laborales y la ampliación del trabajo por cuenta propia, son las reformas más importantes del paquete de cambios. Este proceso de "actualización del modelo socialista cubano", como lo denominó el discurso oficial, se presenta por tanto como un fenómeno de comple- como sociales, con indudables beneficios para la población, pero también con perjuicios para algunos sectores a partir, por ejemplo, de la reducción de subsidios y seguros, y el alza de precios.

El sistema de prensa cubano, inspirado en el modelo socialista soviético y el monopolio estatal sobre los medios de comunicación, condicionan que desde la prensa oficial se construya una imagen del país carente de conflictos y disenso, en la que se resalta el apoyo popular al gobierno y sus disposiciones. En la cobertura nacional del proceso de reformas subyace este contexto.

La prensa extranjera también siguió muy de cerca este proceso desde sus inicios. Pero los medios foráneos abordaron los temas relativos a las reformas desde las diferentes posturas que marcan sus líneas editoriales, generándose así discursos plurales desde los cuales interpretar los cambios en Cuba. No obstante, el control estatal sobre la información en Cuba trasciende a la prensa nacional y se extiende igualmente a los periodistas extranjeros acreditados en la isla, que dependen del Centro de Prensa Internacional (CPI) para acceder a datos, fuentes y eventos.

De ahí el interés por estudiar cómo desde la prensa extranjera se construyó el discurso sobre el plan de reformas socioeconómicas aplicadas en Cuba, particularmente entre agosto del 2010 y julio 
del 2011, pues en ese período se anunciaron y comenzaron a implementarse dos de las más polémicas medidas: la reducción de plazas laborales y la ampliación del trabajo por cuenta propia -como se denomina en Cuba al trabajo no estatal o privado-. El análisis se circunscribe a los diarios mexicanos La Jornada y Reforma, ambos con corresponsales en la isla durante ese período, estructurándose la estrategia metodológica a partir del análisis crítico del discurso.

\section{Marco teórico}

Esta investigación tiene como categoría central de análisis al discurso periodístico, labor centrada en la construcción de aconteceres, fundamentalmente de actualidad informativa, comúnmente denominados "noticias". Esta tarea de construcción de la información sucede en un proceso dinámico de actividades, llevadas a cabo durante la determinación, búsqueda y presentación de los acontecimientos que serán publicados como noticia. Intervienen además en el proceso las rutinas productivas de los medios, las posturas editoriales e intereses particulares de sus dueños, las tradiciones originadas dentro del gremio y la subjetividad de quienes participan en la elaboración de los textos. Estos elementos, que atraviesan la labor periodística, dejan sus huellas en el discurso construido por los medios y en el discurso publicado, por lo que median el consumo informativo de las audiencias.
Los medios resultan instrumentos de poder a través de los cuales los grupos con acceso privilegiado a sus discursos pueden reproducir sus visiones del mundo y reforzar los universos simbólicos existentes. Es precisamente el reconocimiento de la intencionalidad que atraviesa al discurso periodístico, en tanto producto social marcado por múltiples mediaciones determinadas por el contexto de emisión, lo que impulsa un análisis de la noticia desde una postura crítica, tal como lo plantea la propuesta de Teun A. Van Dijk (1996; 2003; 2005; 2012) con su Análisis Crítico del Discurso (ACD).

La propuesta de ACD de Van Dijk resulta un método transdisciplinar que el autor define como un tipo de investigación analítica sobre el discurso que estudia primariamente el modo en que el abuso de poder social, el dominio y la desigualdad, son practicados, reproducidos $\mathrm{y}$ ocasionalmente combatidos por los textos y el habla. Su interés por el discurso periodístico está dado por las complejas relaciones entre el texto de la noticia y el contexto, de manera que una explicación total del estudio del discurso periodístico exige tanto una descripción de las estructuras textuales de la noticia, como una descripción de los procesos de producción y recepción del discurso periodístico en situaciones comunicativas y contextos socioculturales específicos.

Los profesionales de la prensa que intervienen en la elaboración de los textos 
periodísticos comparten opiniones, creencias y conocimientos sociales que van a controlar indirectamente la producción de sus discursos y su representación sobre el mundo. A estas representaciones sociales muy generales, Van Dijk (2005) las denomina "ideologías". En este punto nos apoyamos en el trabajo de John B. Thompson (1998), quien distingue cinco modos generales a través de los cuales opera la ideología: la legitimación, la simulación, la unificación, la fragmentación y la cosificación; presentadas como estrategias típicas que pueden orientarnos en cuanto a formas en que pueden darse los significados en determinado contexto. A continuación se resumen las formas en que se expresan las ideologías (ver la figura 1).

\section{Figura 1}

\begin{tabular}{|c|c|}
\hline Ideologias & Formas en que se expresan \\
\hline Legitimación & $\begin{array}{l}\text { Las relaciones de dominación se presentan como justas y dignas de apoyo. Se sustenta } \\
\text { sobre bases racionales, tradicionales o carismáticas. Operan mediante las siguientes } \\
\text { estrategias de construcción simbólica: } \\
\text { Racionalización: cadena de razonamientos que defienden o justifican relaciones o } \\
\text { instituciones sociales. } \\
\text { Universalización: arreglos institucionales que sirven a intereses de algunos que se } \\
\text { representan como si sirvieran a los intereses de todos. } \\
\text { Narrativización: recuento del pasado y narración del presente como parte de una tradición } \\
\text { que le confiere unidad y cohesión a un grupo a pesar de sus diferencias. }\end{array}$ \\
\hline Simulación & $\begin{array}{l}\text { Cuando se ocultan, niegan o disimulan las relaciones de dominación. Se expresa mediante } \\
\text { sustitución, eufemismo y el empleo de sinécdoques, metonimias y metáforas. }\end{array}$ \\
\hline Unificación & $\begin{array}{l}\text { Construye, simbólicamente, una forma de unidad que abarca a los individuos en una } \\
\text { identidad colectiva, sin considerar sus diferencias. Se manifiesta mediante estandarización } \\
\text { y simbolización de unidad. }\end{array}$ \\
\hline Fragmentación & $\begin{array}{l}\text { A partir del fraccionamiento de individuos y grupos que representan un desafío para los } \\
\text { grupos dominantes. Emplea estrategias de construcción simbólica como: } \\
\text { Diferenciación: énfasis en las diferencias y divisiones entre grupos e individuos. } \\
\text { Expurgación del otro: construcción de un enemigo y el llamado a enfrentarlo. }\end{array}$ \\
\hline Cosificación & $\begin{array}{l}\text { Las relaciones de dominación se presentan como si fueran naturales y permanentes. Se } \\
\text { expresa a través de la naturalización, la eternalización, la nominalización y la pasivización. }\end{array}$ \\
\hline
\end{tabular}

Elaboración propia con información de Thompson (1998). 


\section{Metodología de trabajo}

Este trabajo resulta de una investigación de tipo cualitativa con un diseño de casos múltiples y enfoque inclusivo. Se examinaron los discursos periodísticos relativos a las reformas laborales en Cuba publicados por los diarios mexicanos La Jornada y Reforma en sus versiones impresas durante 12 meses -entre agosto del 2010 y julio del 2011-. Para conocer sobre las particularidades de la cobertura y cómo ese proceso intervino en la construcción de los discursos periodísticos, así como para la triangulación de la información, se realizaron entrevistas abiertas ${ }^{1}$ a los corresponsales de los diarios mexicanos que cubrieron las reformas: Gerardo Arreola ${ }^{2}$, ex corresponsal de La Jornada; y Yolanda Martínez ${ }^{3}$, ex corresponsal de Reforma.

Asimismo, se entrevistó ${ }^{4}$ a la periodista cubana Leticia Martínez ${ }^{5}$, quien durante el 2010 y el 2011 fue jefa de la redacción nacional del diario Granma, órgano oficial del Partido Comunista de Cuba (PCC), teniendo a su cargo la cobertura del proceso de transformaciones del modelo económico cubano. Durante la primera etapa del proceso de reformas, ella y su colega
Yaima Puig ${ }^{6}$ fueron designadas exclusivamente para esas coberturas, mientras el resto de periodistas cubanos y de prensa extranjera no tenían acceso a las reuniones de preparación de las normativas, ni a los especialistas y funcionarios encargados de diseñarlas.

Entre las características del discurso periodístico, Van Dijk (1996) señala que se pueden expresar y señalar los temas a través de los titulares, que aparentemente actúan como resúmenes del texto de la noticia: "Titular y encabezamiento resumen el texto periodístico y expresan la macroestructura semántica" (p.83). Al mismo tiempo, es posible encontrar en el texto de la noticia varios niveles de macroestructuras, cada uno derivado del nivel inmediatamente superior. Así, podemos considerar el tema de un párrafo, o de un conjunto de párrafos, por debajo del tema general del texto periodístico, resultando estos en subtemas (Van Dijk, 2012). Basándonos en estos presupuestos, analizamos la forma global del texto, el significado general, los temas y los subtemas desarrollados.

Las figuras retóricas en los discursos son parte de las estructuras sensibles al

\footnotetext{
1 Ver en el anexo 1 algunas de las preguntas realizadas a los corresponsales de los diarios mexicanos.

2 Gerardo Arreola es actualmente jefe adjunto de edición en el diario La jornada. La entrevista se realizó el 7 de abril del 2014, en la sede de La jornada, en la Ciudad de México.

3 Entrevista realizada el 24 de junio del 2014, en el Hotel Cohíba, en la Ciudad de La Habana, Cuba.

4 Ver en el anexo 2 algunas de las preguntas realizadas a Leticia Martínez.

5 Leticia Martinez actualmente trabaja como periodista en el Consejo de Ministros. La entrevista se realizó el 22 de junio del 2014 en el Memorial José Martí, en la Plaza de la Revolución, en La Habana, Cuba.

6 Durante el 2010 y el 2011, Yaima Puig se desempeñaba como segunda jefa de la redacción nacional del diario Granma. Esta periodista ofreció respuestas escuetas e imprecisas que no aportaron elementos de utilidad para este estudio.
} 
contexto y establecen el modo en que los periodistas elaboran sus discursos y configuran los temas que abordan. Entre las figuras retóricas se contemplaron la metonimia, la hipérbole, la comparación, la metáfora, el símbolo, la antítesis, la personificación, las frases hechas, la adjetivación, la ironía, entre otras, y se analizaron los significados que agregaban al discurso. Por otra parte, asumimos la clasificación de fuentes de Herbert Strenz (como se citó en Alsina, 1989), quien las cataloga como fuentes tradicionales y fuentes no tradicionales, una definición sencilla y global, que permitió clasificar y posteriormente evaluar el empleo de las voces presentes en el discurso periodístico que nos ocupa.

El corpus de análisis arrojó una muestra de 31 materiales periodísticos, compuesta por 16 informaciones de La Jornada y 15 de Reforma. Se aplicó el ACD únicamente a los textos escritos, pues interesaba centrarnos en el modo en que se articularon las estrategias discursivas lingüísticas para relatar el tema de las reformas laborales en Cuba. Para realizar el ACD a cada texto noticioso elaboramos un cuadro que correlacionara las dimensiones de la categoría analítica con sus observables y con las unidades de observación (ver la figura 2).

\section{La Jornada y Reforma: conflictos de una cobertura}

Los medios de comunicación estatal en del Estado para reproducir y legitimar su discurso. Mientras, los medios de comunicación independientes en línea (on line) tienen tan poca incidencia dentro del país, que la visión oficial termina siendo la predominante. Junto a los medios cubanos alternativos que producen información crítica y diversa sobre la isla, la prensa extranjera es otro espacio que tributa a representar una imagen más plural del país.

En relación con nuestra muestra, centrada en las reformas laborales, en La jornada aparecieron publicadas dos informaciones en agosto, cuatro en septiembre, dos en octubre, una en noviembre, tres en diciembre $\mathrm{y}$, durante enero, febrero, marzo, abril, mayo y junio, se registró una por mes, para un total de 18 materiales a analizar. La mayor cantidad de informaciones sobre estos temas se apreció, por tanto, entre agosto y diciembre del 2010.

Por otra parte, durante el mes de octubre del 2010, Reforma dio seguimiento a la convocatoria al VI Congreso del PCC y a asuntos relativos al mismo, como la publicación de los lineamientos y los debates en torno a los cambios. Mientras, entre los meses de septiembre del 2010 a enero del 2011 se concentra la mayor cantidad de notas acerca de las reformas laborales que ocupan nuestro interés, desglosadas del siguiente modo: tres en septiembre, cuatro en octubre, dos en noviembre, tres en diciembre y tres en enero, lo que suman 15 notas de un total de 18. Las otras 
COSETTE CELECIA PÉREZ / REFORMAS LABORALES CUBANAS EN LA PRENSA MEXICANA ANÁLISIS CRITICO DEL DISCURSO DE LA JORNADA Y REFORMA / PP. 103-126 https://doi.org/10.18800/conexion.201901.005 Recibido: 2019-02-12. Aceptado: 2019-05-30

Figura 2

\begin{tabular}{|c|c|c|c|}
\hline $\begin{array}{l}\text { Dimensiones de la } \\
\text { categoría analítica }\end{array}$ & \multicolumn{2}{|c|}{ Observables } & Unidades de observación \\
\hline \multicolumn{4}{|l|}{ 1.Estructura textual } \\
\hline \multicolumn{4}{|l|}{ 1.1. Macroestructuras semánticas } \\
\hline 1.1.1Temas y subtemas de la noticia & & & Titulares/Bajantes/Sumarios \\
\hline \multicolumn{4}{|l|}{ 1.2. Significados locales } \\
\hline 1.2.1. Estrategias discursivas & $\begin{array}{l}\text { Metonimia } \\
\text { Sinécdoque } \\
\text { Hipérbole } \\
\text { Comparación } \\
\text { Metáfora }\end{array}$ & $\begin{array}{l}\text { Contradicción } \\
\text { Personificación } \\
\text { Frases hechas } \\
\text { Ironía } \\
\text { Adjetivación }\end{array}$ & Texto global (escrito) \\
\hline 1.2.2. Ideología de representación & $\begin{array}{l}\text { Legitimación } \\
\text { Reificación } \\
\text { Disimulo }\end{array}$ & $\begin{array}{l}\text { Fragmentación } \\
\text { Exotismo } \\
\text { Unificación }\end{array}$ & Texto global (escrito) \\
\hline $\begin{array}{l}\text { 1.2.3. Estrategias de construcción } \\
\text { simbólica }\end{array}$ & $\begin{array}{l}\text { Racionalización } \\
\text { Narrativización } \\
\text { Eufemismo } \\
\text { Naturalización } \\
\text { Expurgación de }\end{array}$ & $\begin{array}{l}\text { Universalización } \\
\text { Desplazamiento } \\
\text { Tropos } \\
\text { Eternalización } \\
\text { tro }\end{array}$ & Texto global (escrito) \\
\hline 1.2.4. Fuentes periodísticas & $\begin{array}{l}\text { Fuentes tradicic } \\
\text { Fuentes no trac }\end{array}$ & $\begin{array}{l}\text { ales } \\
\text { ionales }\end{array}$ & Texto global (escrito) \\
\hline 1.2.5. Géneros Periodísticos & $\begin{array}{l}\text { Nota informativ } \\
\text { Nota ampliada } \\
\text { Reportaje }\end{array}$ & & Texto global (escrito) \\
\hline \multicolumn{4}{|l|}{ 2. Estructura gráfica } \\
\hline 2.1. Saliencia del trabajo & $\begin{array}{l}\text { Número de cara } \\
\text { Titular en porta } \\
\text { Número de pág } \\
\text { aparece el traba } \\
\text { Emplazamiento } \\
\text { izquierda, arriba } \\
\text { Titulares (en co } \\
\text { tamaño o no) } \\
\text { Bajantes } \\
\text { Fotografías (cu } \\
\text { tamaño, en colo } \\
\text { Gráficas }\end{array}$ & $\begin{array}{l}\text { a en el que } \\
\text { n plana (derecha, } \\
\text { abajo) } \\
\text { tes o no, a gran } \\
\text { tas, en qué }\end{array}$ & Todo el diario \\
\hline
\end{tabular}

Elaboración propia. 
tres informaciones aparecieron, una en agosto, otra en febrero y la última en julio.

En el discurso público aparecido en los medios de comunicación oficiales al abordar las reformas, se aludía a la inmutabilidad de la Revolución, elemento constante en los discursos del presidente de la República, así como en las intervenciones de los funcionarios. En estos discursos también se enfatizaban los logros del proceso como conquistas invariables y se omitieron las afectaciones posibles, o en curso, en el ámbito social. La constante evocación de la gesta revolucionaria, así como de los héroes y líderes históricos, también caracterizó el discurso oficial. Con esas alusiones se tributaba a la reproducción de un imaginario común construido en torno a la Revolución.

Leticia Martínez refirió que las decisiones sobre qué palabras emplear para nombrar los cambios, las revisiones de los trabajos, e incluso los temas y sus líneas editoriales, las decidían los miembros de la Comisión de Implementación de los Lineamientos de la Política Económica ${ }^{7}$.

Al trabajo por cuenta propia nunca se le llamó 'trabajo privado'. Incluso a veces nosotras usábamos el término cuentapropista, o cuentapropismo, y no era un término querido. Era 'traba- jo no estatal', 'trabajador por cuenta propia', el 'sector no estatal' y no era una decisión de nosotras, sino de las sugerencias de tratamiento de la información que nos daban en las reuniones con las comisiones que se crearon al principio, y en las que se realizaba una revisión de los trabajos. Con ellos veíamos ese tipo de conceptos, cosas políticas: lo que es bueno decir, lo que no es bueno decir. $\mathrm{Y}$ al periódico le quedaban las cosas más bien de redacción (entrevista a Leticia Martínez).

Los medios de comunicación nacionales se abocaron a la construcción de una imagen de solidaridad y apoyo a las reformas mediante la presentación de Vox Populi, en donde aparecían diferentes personas opinando, siempre favorablemente, acerca de las transformaciones. Un apoyo al proceso de cambios que se resume en apoyo a "la Revolución", donde el compromiso con las trasformaciones puede leerse asimismo como compromiso con el proceso y con el país. Sin embargo, en el contexto cubano de las reformas, las tensiones están latentes y se identifican a través de discursos críticos que en La Jornada y en Reforma tuvieron voz.

En general, la prensa acreditada en Cuba ha cubierto las reformas mejor que ninguna otra prensa, mejor que

7 En la Comisión de Implementación de los Lineamientos de la Política Económica trabajan especialistas y funcionarios de diferentes ministerios, instituciones y organismos del Estado, encargados de diseñar las nuevas normativas y de velar por su aplicación. Entre ellos se encontraba el entonces ministro de Economía, Marino 
los enviados especiales y mucho mejor que la prensa nacional. Cuba tiene periodistas con muy buena formación y con unas ganas de hacer buen periodismo que aprovechan a la primera. La prensa nacional no ha hecho una mejor cobertura de los cambios de esta última década porque no ha podido, lo mismo que nosotros, que no lo hacemos mejor porque no podemos (entrevista a Yolanda Martínez).

Durante la cobertura de las reformas laborales implementadas por el gobierno de Raúl Castro en Cuba primaron los comunicados oficiales. La voz del gobierno, a través del diario Granma, sustituyó muchas veces otros modos de acceso a la información para los corresponsales mexicanos.

Los editores de Reforma querían información constante sobre el proceso y no había material para elaborar esas noticias. Primero, una sequía de fuentes enorme, y luego, si una quiere hacer un trabajo balanceado sobre cualquier tema, y si quieres dar la versión de gente oficialista, que están en todo su derecho a expresarse, no puedes juntarlas en el reportaje con fuentes disidentes (entrevista a Yolanda Martínez).

Para Gerardo Arreola, de La Jornada, la información oficial constituía la base, pero después buscaba fuentes no oficiales como iniciativa personal.
Acudía a fuentes que no podía citar porque son fuentes que uno va conociendo y que acceden a hablar, pero no están autorizados para hacerlo. Eran conversaciones informales con amigos y las usaba para contrastar. Así que entre mis trabajos hay una parte importante de fuentes sin citar (entrevista a Gerardo Arreola).

Los corresponsales fueron reprendidos por funcionarios del CPI cuando empleaban términos diferentes a los definidos por las voces oficiales de la isla y también cuando abordaban la noticia desde enfoques que no se correspondían con los pautados por poder. Todo esto al tiempo que las demandas de sus diarios, en desencuentro con los requerimientos del CPI, agudizaban las tensiones y conflictos de los periodistas.

Creo que un lector del 2050 que quiera enterarse de lo que ha pasado en Cuba en todas estas décadas va a tener que recurrir a las hemerotecas de prensa extranjera. Me temo que si lo intenta en las hemerotecas de prensa nacional no se va a enterar de casi nada, porque hay un montón de cosas importantísimas que la prensa nacional no ha tratado (entrevista a Yolanda Martínez).

\section{Macroestructuras semánticas en La}

Jornada y Reforma

De los 16 materiales periodísticos de $L a$ Jornada analizados, solo uno apareció 
anunciado en portada. El 2 de agosto del 2010, la primera plana de ese diario otorgaba gran saliencia al titular: "Eliminarán en Cuba un millón de puestos de burócratas", seguido de los bajantes: "Se reanudarán permisos para autoempleo y creación de microempresas", y: "Raúl Castro: es 'un cambio estructural y de concepto' en la economía”. En portada quedaba expresada, de manera sintética, parte medular de los cambios que acapararían la atención del diario en los meses subsiguientes. El modo directo, explícito y categórico que distingue a esas macroestructuras semánticas que inauguran la muestra de La Jornada, será uno de los sellos distintivos del tratamiento que dio el diario al tema de las reformas socioeconómicas en Cuba.

Estos son algunos de los ejemplos en los que las macroestructuras semánticas principales de la noticia, en La Jornada, se caracterizan por ser informativas, claras y precisas: "Raúl Castro anuncia cambios en el modelo cubano"; "Gravan venta particular de frutas y verduras en Cuba: 5\%, el impuesto"; "El gobierno cubano reorganizará y compactará el sistema de Salud"; "Cuba comienza este mes medio millón de despidos en 5 ministerios"; "Apertura en Cuba de oferta minorista de azúcar y arroz por aumento de la demanda"; y "El gobierno cubano permitirá a las microempresas contratar mano de obra”.

No obstante, muchas veces esos titulares fueron acompañados de cintillos y bajan- dad de la información. Tal es el caso de la noticia publicada el 4 de enero del 2011 con el tema de la reducción de plazas. El titular: "Cuba comienza este mes medio millón de despidos en 5 ministerios", venía precedido por el cintillo: "También hará efectivas las alzas de precios en artículos de higiene y tarifas de luz", y sucedido por el bajante: "El plan de reforma económica rompe con las líneas de política social que rigieron medio siglo". Si ya el anuncio del inicio de medio millón de despidos, como tema general, resulta impactante y con una connotación negativa por la repercusión que tiene el desempleo como problema social, el poner a dialogar esa información con otros dos elementos noticiosos que afectan directamente a la ciudadanía, incrementa la noción de crisis y conflicto que significa la actualización del modelo económico fundamentalmente para la población.

Precisamente, una de las características del discurso de La Jornada que iremos desarticulando es la contraposición del discurso del gobierno de Raúl Castro con el discurso tradicional de la Revolución, como lo evidencia el bajante: "El plan de reforma económica rompe con las líneas de política social que rigieron medio siglo". Esta idea será repetidamente expuesta en los textos del diario a través de diferentes recursos, como el empleo de datos antecedentes y la comparación.

Otro ejemplo en este sentido lo observamos en la nota de La Jornada del 9 de 
septiembre, cuyo titular expone: "Arranca el 'nuevo modelo cubano' con más de medio millón de despidos”. Antes un cintillo resaltaba: "Cientos de miles de trabajadores se moverán al sector privado en los próximo años”. Mientras dos bajantes acotaban: "El Estado retendrá áreas estratégicas como el petróleo, la biotecnología y el turismo, entre otras”, y: “La nueva política laboral elimina el seguro de desempleo que cubría hasta el 60\% del salario”. En la misma cuerda encontramos el titular del 26 de octubre: "Entra en vigor la reforma económica en Cuba; adiós al seguro de desempleo". Así se presentó el tratamiento informativo en La Jornada, con el antes y el después de la política social cubana, teniendo como punto de ruptura el plan de reformas impulsado por Raúl Castro.

Reforma, por su parte, con 15 materiales como parte de la muestra, no colocó nunca el tema de las transformaciones socioeconómicas en su portada, pero al abordarlo le otorgó gran saliencia en su sección Internacional -a partir de titulares en gran tamaño, bajantes, fotos y resúmenes que acompañaban los trabajos periodísticos-, distinguiéndose por el uso recurrente de titulares que constituyen figuras retóricas como metáforas y sinécdoques que, interpretadas teniendo en cuenta el contexto, la postura editorial del diario y las declaraciones de la corresponsal, denotan una marcada ironía.

Ejemplos de macroestrucuras semánticas en las que se aprecia el sarcasmo los en- contramos en la nota del 14 de septiembre del 2010, publicada bajo el titular: "Hacen en Cuba guiño a la IP [Iniciativa Privada]”, seguido del bajante: “Confirman recorte de medio millón de empleos estatales para mejorar eficiencia”. En el titular identificamos una metáfora, según la cual en Cuba se "coquetea” con la iniciativa privada, sin asumir un compromiso explícito con ella. Además, hacer un guiño es, tanto en Cuba como en México, un gesto de cierta picardía que puede significar tanto un saludo informal como un flirteo o insinuación. Hacer "un guiño" a algo, o a alguien, puede significar también hacer un homenaje, o reverencia, a ese elemento; aludirlo, pero no de modo explícito. De tal manera, entendemos que el guiño cubano a la IP que refiere Reforma está evaluando una postura de las autoridades de la isla hacia la iniciativa privada que no es clara, ni manifiesta.

Otro ejemplo del empleo de las ironías y las metáforas en las macroestructuras de Reforma lo encontramos en el reportaje que aborda el tema de la ampliación del trabajo privado, el 25 de septiembre del 2010. El texto, precedido por el cintillo: "Dará en octubre luz verde a 178 oficios privados”, contaba con el titular: "Legaliza Cuba hasta a payasos”. Finalmente, antes del sumario, colocaron el bajante: "Temen habitantes por insumos caros y alta carga fiscal en nuevos negocios”.

La primera macroestructura resulta una metonimia, pues la "luz verde" puede 
asociarse por causa y efecto: luz verde (causa o señal) que significa permiso para pasar (efecto). En esa frase nuevamente hay un sujeto omitido que se encuentra luego en el titular y que de manera sinecdótica vuelve a equiparar Cuba con el gobierno cubano. El gobierno cubano, por tanto, autoriza 178 oficios. La sinécdoque "Legaliza Cuba hasta a payasos", alude a las numerosas nuevas labores certificadas por el gobierno cubano para ser ejercidas por particulares. Referirse a los payasos denota ironía y otorga a la frase una coloquialidad que se repite en otros titulares de la muestra de Reforma, rehuyendo de los tonos serios que caracterizaron a las macroestructuras de La Jornada.

En el mes de diciembre del 2010, en dos notas que trataron las reducciones de plantillas, encontramos también macroestructuras semánticas cargadas de ironía. El día 6 el titular anunciaba: "Quiere Cuba exportar médicos", una frase que además recurre otra vez a significar el todo por la parte al poner "Cuba" como equivalente de "el gobierno cubano". Asimismo, la oración presupone una personificación, pues se le atribuye a la isla la capacidad de desear o pretender algo, al tiempo que se asocia al personal médico de la isla con productos exportables. Tal pareciera por el titular que para el gobierno de la isla sus profesionales de la salud son cosificables en el contexto de ajustes económicos. El día 11 de ese mismo mes, volvía Reforma sobre las anunciadas re- con el titular: "Amplía Cuba 'exportación' de expertos", frase en la que las comillas introducen la distancia irónica.

Una noticia con un titular cargado de humor en Reforma es la del 21 de enero del 2011: "Toman los cubanos gusto a changarros", se anuncia en grandes letras. Acompañan la coloquial frase el cintillo: "Proliferan microempresas con reformas de Raúl Castro", y el bajante: "Admiten en la Isla que un negocio propio puede hasta triplicar el salario promedio"; este último dato argumenta la proliferación de las microempresas y el deseo de los cubanos por hacerse de su propia tiendita. La referencia a los ingresos de particulares, superiores a los de los trabajadores estatales, vuelve a presentarse en las macroestructuras de la última nota de la muestra de Reforma, publicada el 13 de julio del 2011: "Repunta en Cuba ingreso privado", enuncia el titular, precedido por el cintillo: "Ganan particulares más que empleados estatales", seguido por el bajante: "Prevé el gobierno que en cinco años la IP represente el 50\% del PIB nacional”.

\section{Temas y subtemas}

Para este estudio se seleccionaron de antemano los temas a analizar, de modo que todos los materiales de la muestra se inscriben dentro del macrotema "Reformas sociopolíticas del gobierno de Raúl Castro" y abordan los temas específicos de la ampliación de la IP y la reducción de plazas laborales. Mientras, algunos materiales abordan simultáneamente los dos 
temas, de manera que establecimos tres temas en los que se inscriben los trabajos periodísticos de la muestra:

1- La ampliación de la IP.

2- La reducción de plazas laborales.

3- La ampliación de la IP como alternativa a la reducción de plazas laborales (ver la figura 3).

Por diarios, siete de los materiales de $\mathrm{La}$ Jornada se ubicaron dentro del tema de "La ampliación de la IP”, cinco se centraron en "La reducción de plazas laborales" y cuatro abordaron "La ampliación de la IP como alternativa a la reducción de plazas laborales”. Además, en La Jornada se identificaron los subtemas:

1- La eliminación de subsidios estatales y/o la eliminación de beneficios de la seguridad social (en cinco trabajos periodísticos).
2- Cambios generales en el modelo económico cubano (en cuatro materiales).

3- Inestabilidad de la política cubana hacia la IP (en dos materiales).

4- Cambios en sistema tributario para la IP (en dos materiales).

5- Ruptura de las reformas del gobierno de Raúl Castro con política anterior de la Revolución (en dos materiales).

En Reforma clasificamos ocho de los materiales dentro del tema de "La ampliación de la IP", cinco se centraron en "La reducción de plazas laborales" y otros dos en "La ampliación de la IP como alternativa a la reducción de plazas laborales". Este diario se distinguió por centrarse en el abordaje del tema principal sin agregar en la mayoría de los casos elementos complementarios, como datos antecedentes. Por esa razón, identificamos solo en cinco trabajos el tratamiento de los siguientes subtemas:

Figura 3. Presencia de temas en la muestra general

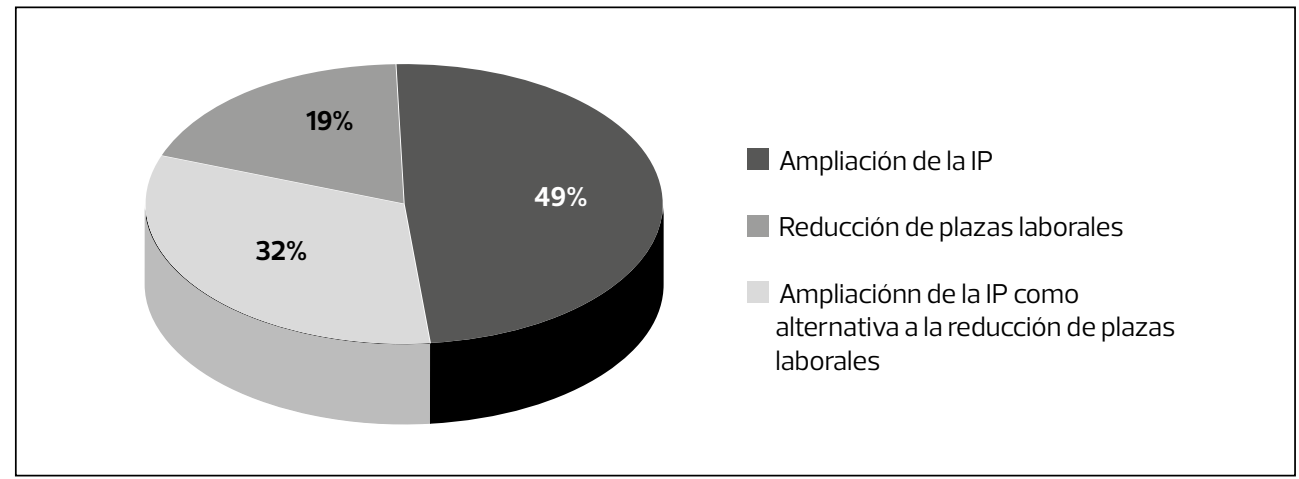


1- La reducción de plazas laborales (en dos materiales).

2- La ampliación de la IP como alternativa a la reducción de plazas laborales (en un material).

3- Cambios generales en el modelo económico cubano (en un material).

4- Deterioro del sistema de salud en la isla (en un material).

\section{Significados locales: las estrategias discursivas}

Con el empleo de sinónimos, los diarios mexicanos estudiados se distanciaron de las denominaciones empleadas por el dis- curso oficial al abordar las reformas, pese a que el Estado cubano trataba de ajustar las reseñas hacia el exterior de modo que fueran afines a sus propios marcos editoriales. Tanto en La Jornada como en Reforma fueron frecuentes las metonimias, por ejemplo, para referirse al promovido sector no estatal y sus miembros (ver la figura 4).

Otras metonimias recurrentes aparecieron en los dos diarios al referirse a la reducción de plazas laborales (ver la figura 5).

Las medidas socioeconómicas del gobierno de Raúl Castro también recibieron diferentes denominaciones. El empleo de sinónimos en estos casos ofrece una lectura crítica sobre los cambios por parte de los corresponsales (ver la figura 6).

Figura 4

\begin{tabular}{|l|l|l|}
\hline \multicolumn{1}{|c|}{ Diarios } & Denominación/ Referente & \multicolumn{1}{c|}{ Metonimias } \\
\hline La Jornada & Sector no estatal & $\begin{array}{l}\text { "privados", "emprendedores", "trabajadores no estatales", } \\
\text { "microempresa privada", "negocios personales", "sector } \\
\text { privado", "trabajadores por cuenta propia" }\end{array}$ \\
\hline Reforma & Sector no estatal & $\begin{array}{l}\text { "Pequeñas y medianas empresas (Pymes)", "Iniciativa } \\
\text { Privada (IP)", "microempresarios", "autoempleados", } \\
\text { "trabajadores por cuenta propia" }\end{array}$ \\
\hline
\end{tabular}

Elaboración propia.

Figura 5

\begin{tabular}{|c|l|l|}
\hline \multicolumn{1}{|c|}{ Diarios } & Denominación / Referente & \multicolumn{1}{c|}{ Metonimias } \\
\hline La Jornada & $\begin{array}{l}\text { Reducción de plazas } \\
\text { laborales }\end{array}$ & $\begin{array}{l}\text { "ajuste laboral", "reducción de empleos", "reducción de } \\
\text { plantillas infladas", "recorte", "despidos" }\end{array}$ \\
\hline Reforma & $\begin{array}{l}\text { Reducción de plazas } \\
\text { laborales }\end{array}$ & $\begin{array}{l}\text { "empleados excedentarios", "puestos públicos excedentes", } \\
\text { "trabajadores que sobran", "trabajadores al paro", "recorte", } \\
\text { "despidos" }\end{array}$ \\
\hline
\end{tabular}


Figura 6

\begin{tabular}{|c|l|l|}
\hline \multicolumn{1}{|c|}{ Diarios } & Denominación / Referente & \multicolumn{1}{c|}{ Metonimias } \\
\hline La Jornada & Medidas socioeconómicas & $\begin{array}{l}\text { "reformas", "plan de reformas", "reforma económica", } \\
\text { "medidas del gobierno de Raúl" }\end{array}$ \\
\hline Reforma & Medidas socioeconómicas & $\begin{array}{l}\text { "paquete de reformas", "nueva política de realismo } \\
\text { económico", "nuevo plan de gobierno", "plan de } \\
\text { racionalización económica" }\end{array}$ \\
\hline
\end{tabular}

Elaboración propia.

En la información del 29 de diciembre del 2010, el texto de La Jornada aclara: "las reformas, que el gobierno cubano califica de 'actualización del modelo socialista' (...)", marcando los límites entre el discurso oficial cubano y el propio. Mientras en Reforma, en la nota del 13 de julio del 2010, se afirma que el plan de transformaciones "busca modernizar el sistema cubano dejando atrás el obsoleto socialismo de corte soviético", aportando una interpretación de la corresponsal a partir de los elementos que se manejan en la información, pero no siendo una cita de fuentes oficiales ni una referencia al discurso oficial.

Tanto en La Jornada como en Reforma se observó el empleo de sinécdoques que referían el todo por la parte, fundamentalmente al presentar "Cuba" como equivalente de "el gobierno cubano". En La Jornada clasificamos numerosas comparaciones dentro de los recursos empleados en el discurso y en la mayoría de los casos esas comparaciones, desarrolladas a lo largo de los textos, expresaban una contradicción dada por la divergencia entre las políticas previas y la reforma ac- tual. La comparación como estrategia discursiva se identificó en 14 de los 16 textos analizados de La Jornada, registrándose en la mayoría de esos trabajos como mínimo dos ejemplos.

Entre los fragmentos que ejemplifican estos hallazgos, podemos citar varios presentes en la nota del 25 de septiembre del 2010. Por ejemplo, hay un trabajo de seis párrafos, de los cuales cuatro constituyen información antecedente acerca de las políticas estatales hacia la IP, centrada en datos de la década del 90 y del 2004. "El trabajo por cuenta propia (...) fue parte de las reformas que ayudaron a Cuba a remontar la crisis surgida del derrumbe soviético, pero el sector languideció a finales de la década pasada por la dureza de reglamentos e impuestos (...)", expone el texto. En este trabajo el discurso no solo se articula a partir del contraste entre políticas previas y actuales, sino que se presenta desde un enfoque positivo a la IP que se relanza, revistiéndose con tintes negativos la contención anterior hacia el sector.

Sin embargo, también encontramos ejemplos que imprimen una valoración nega- 
tiva a las transformaciones relativas a la eliminación de empleos, subsidios y beneficios de la seguridad social. Algunos de estos casos son "la nueva oferta de arroz y azúcar es más cara, sin comparación, que en la libreta"; "en la nueva política laboral, una novedad será la eliminación del seguro de desempleo (...)"; "la colocación de los despedidos ya no es una carga pública como antes"; "la nueva fórmula modifica sustancialmente el criterio predominante en la política de empleo en Cuba durante medio siglo”.

El análisis de metáforas en el cuerpo de las noticias permitió conectar sus significados con la reproducción de ideologías de representación en el discurso (ver la figura 7 ).

\section{Ideologías de representación}

En La Jornada se identificó la legitimación como estrategia de construcción simbólica en 10 textos periodísticos, en otros cuatro se apreció conjuntamente legitimación y fragmentación, y en dos apareció solo la fragmentación. En Reforma apareció la legitimación en 13 informaciones y en dos se combinaron elementos de legitimación y fragmentación como ideologías de representación. El resto de las estrategias de construcción simbólica que describe Thompson (1998) no se identificaron en la muestra analizada (ver la figura 8).

En La Jornada, al analizar el modo en que se manifestó la legitimación como estrategia de construcción simbólica, encontra-

Figura 7

\begin{tabular}{|l|l|l|}
\hline Diarios & $\begin{array}{l}\text { Estrategias discursivas } \\
\text { frecuentes }\end{array}$ & Ejemplos \\
\hline \multirow{4}{*}{ La Jornada } & Comparación & $\begin{array}{l}\text { "esta fórmula modifica una política anterior..." } \\
\text { "quedó descartada tácitamente la línea anterior" } \\
\text { "subrayando el giro que ha dado la política" }\end{array}$ \\
\cline { 2 - 3 } & Sinécdoque & "Cuba" como equivalente de "el gobierno cubano" \\
\cline { 2 - 3 } & Frases hechas & $\begin{array}{l}\text { "preparando el terreno para el despido masivo", "entrar en } \\
\text { vigor", "ser la hoja de ruta" }\end{array}$ \\
\hline \multirow{2}{*}{ Reforma } & $\begin{array}{l}\text { "exportación de médicos", "Granma denunció el } \\
\text { 'peloteo'...", "echar a andar la economía del país } \\
\text { golpeada..." }\end{array}$ \\
\cline { 2 - 3 } & Adjetivación & $\begin{array}{l}\text { "deprimida economía", "cambios estructurales", "variante } \\
\text { estigmatizada" }\end{array}$ \\
\cline { 2 - 3 } & Sinécdoque & "Cuba" como equivalente de "el gobierno cubano" \\
\cline { 2 - 3 } & &
\end{tabular}


Figura 8. Ideologías de representación

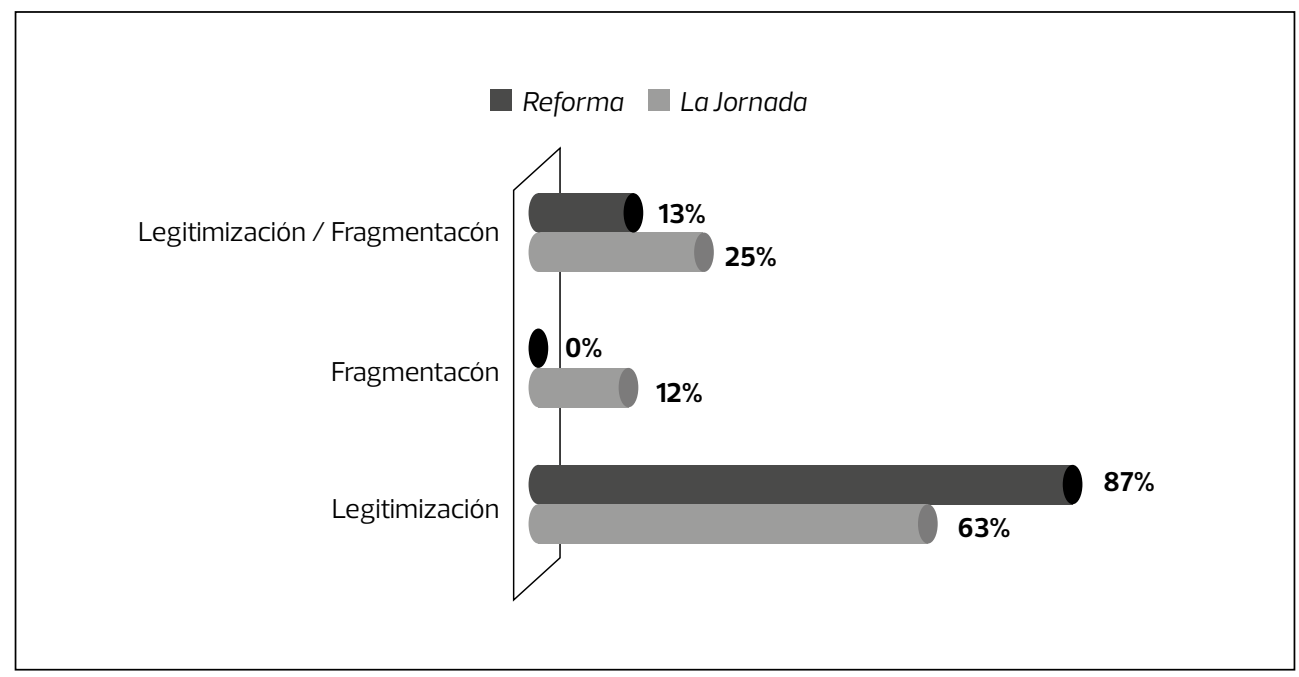

Elaboración propia.

mos que esta operó siempre mediante la racionalización como estrategia discursiva, a partir de la exposición de elementos de contextualización que proporcionan una serie de razonamientos que avalan la aplicación de las reformas socioeconómicas. La estructuración del discurso periodístico en esos casos abordó las reformas a partir de citas directas a fuentes oficiales. Al retomar el discurso oficial cubano, sin cuestionamientos, ni contrastación de fuentes, se están refrendando esas voces y lo que expresa su discurso.

En la nota de La Jornada del 20 de septiembre del 2010, a partir de citas de la declaración de un dirigente sindical, se remarca: "los despidos y el trabajo no estatal no suponen cambios en la política”, "la IP es una alternativa a los despidos", "las reformas laborales son necesarias" y “la CTC apoya las reformas". Además, en este trabajo se presentan las causas de la necesidad de las medidas: "el paternalismo estatal que prevaleció medio siglo", "la ineficiencia", "los subsidios excesivos" y "el embargo estadounidense”.

También en el discurso de La Jornada se imbricó legitimación y fragmentación. Esto ocurrió en cinco trabajos en los que se daba la fragmentación a partir de la presentación en los textos de los datos antecedentes que ejemplificaban la línea de política social guiada por el gobierno de Fidel Castro, usualmente a partir de una narrativización, alternando dicha data con la información de actualidad acerca de la nueva línea promovida por su hermano Raúl, en un contrapunteo marcado por la organización del discurso, que a la vez que establecía una 
diferenciación, legitimaba las actuales disposiciones.

En los cinco trabajos, al mismo tiempo que la fragmentación, se apreció una legitimación de las actuales políticas de cambio a partir de la presentación de la voz de Raúl Castro, y de otras fuentes oficiales como el diario Granma, mediante citas directas y paráfrasis. Así, se ofrecen cifras sobre el esperado crecimiento de la IP ("En los próximos 5 años podría haber 2.5 millones de trabajadores no estatales, calcula ministra") y se refieren a la nueva actitud positiva hacia el sector ("no estigmatizar al sector", "apoyar su crecimiento", "eliminación de barreras legales"). Mientras, la narrativización se observó en la presentación de datos antecedentes que, a la par que tributaban a la fragmentación a partir de la diferenciación, resaltaban en la mayoría de los casos la legitimidad a las reformas que aparecían como una superación de un pasado de inestabilidad y constricción hacia las iniciativas de trabajo particular.

Finalmente, en un trabajo de La Jornada identificamos la presencia de la fragmentación como única ideología de representación. Esta nota ampliada, que aborda "La ampliación de la IP" como alternativa a la reducción de plazas -catalogada como "despidos masivos"-, no solo enfatiza los perjuicios de la ruptura de las reformas con una política de seguro social altamente beneficiosa para los trabajadores, sino que resalta los aspectos negativos de la política de flexibilización de la IP. La fragmentación, también en este caso, se dio a partir de comparaciones, ahora a partir de datos puestos en contraste. Resalta en este punto el titular: "Entra en vigor la reforma económica en Cuba; adiós al seguro de desempleo".

En el diario Reforma la legitimación se identificó fundamentalmente a partir de la racionalización como estrategia de construcción simbólica. Los datos, las cifras y los argumentos que sustentaban la idea de la necesidad de las trasformaciones socioeconómicas, así como sus esperados beneficios, fueron recurrentes en el discurso de este rotativo. Apoyó a la construcción de esa legitimidad la presencia de tablas y gráficas que, con datos "duros", corroboraban el beneficio de las transformaciones. Por ejemplo, la nota ampliada del 13 de julio del 2011 se publicó acompañada de una gráfica que refleja la brecha salarial entre trabajadores privados y empleados estatales. Según dicha infografía, los trabajadores privados perciben un promedio de 41 dólares mensuales, mientras los estatales ganan un aproximado de 18 dólares por mes (ver la figura 9).

En las noticias de Reforma, la racionalización se observó a partir de la presentación de fuentes oficiales, tanto mediante citas directas como a través de paráfrasis. La mayoría de los textos solo tuvieron como fuentes a voces oficiales, de modo que el discurso oficial cubano tuvo una amplia presencia en el discurso de Reforma. En va- 
Figura 9

\begin{tabular}{|c|c|c|c|}
\hline Diarios & $\begin{array}{l}\text { Ideologías de } \\
\text { representación } \\
\text { frecuentes }\end{array}$ & $\begin{array}{l}\text { Estrategias } \\
\text { discursivas }\end{array}$ & Ejemplos y recursos \\
\hline \multirow{3}{*}{ La Jornada } & Legitimación & Racionalización & $\begin{array}{l}\text { - Citas a fuentes oficiales } \\
\text { - Presentación de datos y cifras } \\
\text { "los despidos y el trabajo no estatal no suponen } \\
\text { cambios en la políica", } \\
\text { "Ia IP es una alternativa a los despidos", } \\
\text { "las reformas laborales son necesarias" }\end{array}$ \\
\hline & \multirow[t]{2}{*}{ Fragmentación } & Diferenciación & $\begin{array}{l}\text { - Políticas tradicionales de la revolución cubana } \\
\text { vs. nuevo modelo impulsado por el gobierno de } \\
\text { Raúl Castro. } \\
\text { "Entra en vigor la reforma económica en Cuba; } \\
\text { adiós al seguro de desempleo". }\end{array}$ \\
\hline & & Narrativización & $\begin{array}{l}\text { - Recuentos } \\
\text { - Presentación de datos antecedentes }\end{array}$ \\
\hline Reforma & Legitimación & Racionalización & $\begin{array}{l}\text { - Presentación de datos, cifras y argumentos } \\
\text { apoyando la necesidad de las trasformaciones } \\
\text { - Se resaltan esperados beneficios de los } \\
\text { cambios para: } \\
\text { "alcanzar la sustentabilidad económica", } \\
\text { "ordenar la economía", "sacar a la isla de la crisis" } \\
\text { - Empleo de tablas, gráicicas y resúmenes } \\
\text { - Citas a fuentes oficiales }\end{array}$ \\
\hline
\end{tabular}

Elaboración propia.

rios de los materiales analizados, el discurso de este rotativo enfatizó la necesidad de las medidas para "alcanzar la sustentabilidad económica”, "solventar la crisis”, "ordenar la economía”. Insistiendo también en la apertura de la IP como estrategia para "reducir el paro". Todos estos argumentos tributaron a que desde el discurso periodístico de Reforma se legitimaran las medidas del gobierno cubano y a la par al propio gobierno como ejecutor.

En una de las notas de Reforma, la legitimación actuó también a partir de la na- rrativización mediante la presentación en el texto de un recuento de la precaria situación sanitaria antes del triunfo de la Revolución. Esto estableció una comparación con los datos de actualidad acerca del excedente de personal en el sector de la salud que creció considerablemente después de los años 6o. En este ejemplo se resaltan una vez más los beneficios de la medida: "dentro del plan de racionalización económica, que provocará despidos masivos (...) el gobierno pretende elevar la calidad de los servicios del sistema de salud pública". 


\section{Reflexiones finales}

El proceso de construcción de los discursos periodísticos de La Jornada y Reforma estuvo mediado por el control estatal sobre la información en Cuba. El ACD permitió conectar los vínculos entre el contexto social de elaboración y el discurso periodístico de los diarios para acercarnos al funcionamiento de las relaciones de poder en torno a nuestro objeto y el modo en que se expresan en él.

Desde el discurso oficial cubano acerca de las reformas laborales se enfatizó la inmutabilidad de la Revolución, en tanto desde los rotativos mexicanos se resaltó el potencial de cambio que significaban estas medidas. Aunque no apareciera explícitamente, pues la postura oficial de la isla recalcaba constantemente lo contrario, los titulares de La Jornada y de Reforma denotaron una intencionalidad por mostrar que, efectivamente, muchas cosas están cambiando en Cuba.

Desde la prensa nacional cubana el discurso del poder se mostró esquemático y extremadamente cauteloso. El constante empleo de eufemismos confirma el temor de llamar a las cosas por su nombre y la intención de disimular cambios evidentes. Llamar "proceso de disponibilidad" a los despidos y "trabajo por cuenta propia” al trabajo privado da cuenta de ello. Por su parte, la prensa mexicana empleó titulares provocadores que resaltan los elementos conflictivos de las reformas y que, en varios casos, jugaban con el discurso oficial desde una marcada ironía, mientras se refieren a "despidos masivos" y "aumento del trabajo privado" sin rodeos. No obstante, las estrategias discursivas y las construcciones simbólicas de los diarios mexicanos, en general, avalaron el papel de la dirigencia cubana como gestores y protagonistas de las reformas y legitimaron la postura oficial de que las transformaciones laborales eran imprescindibles para la continuidad del proyecto revolucionario.

El ACD permitió poner en diálogo el análisis lingüístico más formal con los modos de apropiación de la realidad cubana por parte de los corresponsales mexicanos, los esquemas discursivos promovidos por el poder de la isla y con los mecanismos mediante los cuales se establece, reproduce y legitima el poder en Cuba, tanto hacia adentro como hacia afuera del país. La existencia de un discurso hegemónico oficialista, determinado por el modelo de prensa existente en Cuba, afín al sistema político, incide en la preeminencia del discurso partidista que, al tiempo que impulsa un proceso de cambios, niega parte fundamental de la esencia de esas transformaciones. De esta manera, la cobertura de las transformaciones socioeconómicas por parte de los diarios mexicanos $\mathrm{La}$ Jornada y Reforma, y la reconstrucción de este proceso en sus páginas, aporta un nuevo ángulo para leer, desde los discursos mediáticos, el proceso de cambios que experimenta Cuba. 


\section{REFERENCIAS}

Alsina, M. (1989). La construcción de la noticia. Barcelona / Buenos Aires / México D.F.: Paidós comunicación.

Arreola, G. (7 de abril del 2014). Entrevista realizada para este estudio a Gerardo Arreola, ex corresponsal de La Jornada en Cuba. Entrevistadora: Cosette Celecia.

Martínez, Y. (24 de junio del 2014). Entrevista realizada para este estudio a Yolanda Martínez, ex corresponsal de Reforma en Cuba. Entrevistadora: Cosette Celecia.

Thompson, J. B. (1998). Ideología y cultura moderna. Teoría crítica social en la era de la comunicación de masas. México D.F.: Universidad Autónoma Metropolitana (UAM).

Van Dijk, T. A. (1996). La noticia como discurso. Comprensión, estructura y producción de la información. Barcelona: Paidós.

Van Dijk, T. A. (2003). La multidisciplinaridad del análisis crítico del discurso: un alegato en favor de la diversidad. En R. Wodak y M. Meyer (Eds.), Métodos de análisis crítico del discurso (pp. 143-177). Barcelona: Gedisa.

Van Dijk, T. A. (2005). Ideología y análisis del discurso. Utopía y Praxis Latinoamericana, 29 (10), 9-36.

Van Dijk, T. A. (2012). Estructuras y funciones del discurso. México D.F.: Siglo veintiuno editores.

\section{ANEXO 1}

Algunas de las preguntas incluidas en las entrevistas abiertas realizadas a los corresponsales Gerardo Arreola (La Jornada) y Yolanda
Martínez (Reforma) fueron las siguientes:

1- ¿Cómo fue para usted abordar el proceso de reformas socioeconómicas en Cuba, iniciado por Raúl Castro en 2008?

2- ¿Cómo experimentó la mediación del Centro de Prensa Internacional y del Comité Central del Partido en su cobertura de las reformas?

3- ¿Cómo conciliaba los intereses y exigencias de su medio con los del CPI?

4- ¿Qué fuentes de información fundamentales empleó en esa etapa? ¿Qué presencia tuvieron Granma y las notas oficiales del CCP entre sus fuentes?

5- ¿Cree que la agenda mediática pautada por Granma, que es afín a la pautada por el CCP, influye en el trabajo de los corresponsales extranjeros? ¿Influyó en el suyo?

6- ¿Alguna vez tuvo problemas por traspasar las normas establecidas por el CPI en Cuba?

7- ¿Acudía a los llamados "disidentes" en Cuba para que fueran fuentes de información en sus trabajos?

8- ¿Cómo valora la cobertura informativa que dio la prensa oficial cubana a la reducción de plazas laborales y la ampliación del trabajo privado?

9- ¿Por qué cree que persiste la dicotomía entre lo que pide Raúl Castro, acerca de potenciar el papel de la prensa, y lo que sucede en la práctica?

\section{ANEXO 2}

Algunas de las preguntas incluidas en las entrevistas abiertas realizadas a la periodista cubana Leticia Martínez fueron las siguientes:

1- ¿Qué exigencias profesionales te demandó la cobertura del trabajo de las reformas? 
2- ¿Crees que en esta segunda etapa del trabajo por cuenta propia en Cuba, a diferencia de en los años 9o, ha habido una mayor voluntad política de promover el trabajo no estatal?

3- ¿Específicamente de dónde venía la orientación de la cobertura y la designación de ustedes para hacerla?

4- ¿Consideras que como corresponsal de Granma designada para la cobertura de estos temas tuviste privilegio en el acceso a las fuentes?

5- ¿Tienes conocimiento de cómo fue el acceso de la prensa extranjera a estos temas?

6- Además de las fuentes oficiales que has citado, ¿empleaste también fuentes no oficiales en tus trabajos?

7- ¿Cómo valoras el tratamiento que se le dio en los medios nacionales a la flexibilización del trabajo por cuenta propia y a la reducción de plantillas?

8- ¿Qué opinión tienes del tratamiento de estos mismos temas en la prensa extranjera?

9- ¿Cómo valoras el llamado hecho por Raúl Castro a un periodismo más crítico, más abierto, sin secretismos, en el contexto de esta cobertura? 